\title{
A TOMADA DE DECISÃO PARA O DESENVOLVIMENTO DE NOVOS PRODUTOS: UM ESTUDO NA INDÚSTRIA DA MODA DE BELO HORIZONTE
}

\section{DECISION MAKING FOR NEW PRODUCT DEVELOPMENT: A STUDY IN THE FASHION INDUSTRY OF BELO HORIZONTE}

\author{
Rita de Cássia Leal Campos \\ Universidade Federal de Lavras - UFLA - MG \\ rita.campos.adm@gmail.com \\ Uajará Pessoa Araújo \\ Centro Federal de Educação Tecnológica de Minas Gerais - CEFET-MG \\ uajara@yahoo.com.br \\ Lilian Bambirra de Assis \\ Centro Federal de Educação Tecnológica de Minas Gerais - CEFET-MG \\ lilianbassis@hotmail.com
}

Submissão: $22 / 10 / 2020$

Aprovação: 24/03/2021

\section{RESUMO}

Este artigo teve como objetivo investigar como ocorre a tomada de decisão dos gestores na indústria de moda feminina de Belo Horizonte no processo de planejamento para o desenvolvimento de novos produtos. A pesquisa tem abordagem qualitativa e se classifica como descritiva. Para a coleta de dados, foram realizadas sete entrevistas semiestruturadas com gestoras de empresas da indústria da moda. Para a análise dos dados, utilizou-se a análise de conteúdo, contando com o auxílio do software QDA Miner. Os resultados indicaram que o processo decisório na indústria da moda se dá coletivamente e de modo mais informal, seguindo um modelo processual de tomada de decisão. $O$ planejamento para $o$ desenvolvimento de novas coleções geralmente é realizado pelo proprietário da marca com o apoio de sua equipe. Para tomar decisões, os gestores utilizam pesquisas de mercado e de tendências, mas também se baseiam em suas intuições, habilidades e experiências.

Palavras-chave: Indústria da moda. Tomada de decisão. Racionalidade. Modelos de tomada de decisão.

\begin{abstract}
This article aimed to investigate how managers' decision making occurs in the women's fashion industry of Belo Horizonte in the planning process for the development of new products. The research has a qualitative approach and is classified as descriptive. For data collection, seven semi-structured interviews were conducted with managers of fashion industry companies. For data analysis, the content analysis was used, with the aid of QDA Miner software. The results indicated that the decision making process in the fashion industry
\end{abstract}


takes place collectively and more informally, following a procedural model of decision making. The planning for the development of new collections is usually done by the brand owner with the support of his team. To make decisions, managers use market and trend research, but they also rely on their intuitions, skills and experiences.

Keywords: Fashion Industry. Decision Making. Rationality. Decision Making Models.

\section{INTRODUÇÃO}

Sendo um dos setores de maior tradição no segmento industrial, o setor têxtil e de confecção desempenha um papel fundamental no desenvolvimento econômico e social do Brasil. Após a incipiência da indústria têxtil no período colonial, houve uma aceleração do processo de industrialização em decorrência da limitação da capacidade de importação do país, o que estimulou a produção interna (MELO et al., 2007). A abertura do mercado brasileiro no início da década de 1990 repercutiu drasticamente na indústria têxtil e de confecção, dado que o plano Real e o estabelecimento da economia permitiram que empresários reestruturassem e modernizassem parques industriais (FUJITA, 2017).

Alves (2009) esclarece que a indústria da moda é responsável por movimentar a indústria têxtil e de confecções, o que dificulta a delimitação entre elas, sobretudo porque as expectativas dos consumidores aliadas à diversidade de produtos no mercado conceberam o setor de moda e o setor de vestuário como um único e indissociável universo. A moda assume um posicionamento intermediário em razão de sua natureza, como prática econômica e como atividade artística. Transitando entre a indústria e as artes, não somente exerce influência sobre o consumo e a economia como também repercute de maneira peculiar na cultura, transcendendo os limites do vestuário (GODARD, 2010).

Conforme Araújo (2013), a indústria da moda caracteriza-se por ciclos de vida curtos, volatilidade, imprevisibilidade da demanda e grande variedade de produtos. E, uma vez que os produtos se baseiam em tendências constantemente alteradas, o período de lançamento e obsolescência se torna próximo. Em mercados dinâmicos como o da moda, ser flexível e ter a habilidade de respostas rápidas é fator chave para a sustentabilidade econômica das empresas (PACHECO, GOLDMAN, 2019).

Rocha (2016) ressalta que, no contexto da moda, as decisões devem ser mais técnicas e voltadas para o relacionamento entre a empresa e o cliente. Sendo assim, ao gerenciar a tomada de decisão, é preciso compreender as preferências do público-alvo para o alcance do sucesso comercial. Em concordância, Stefanovitz (2011) afirma que os processos de desenvolvimento de novos produtos envolvem diversos pontos de tomada de decisão e, consequentemente, dependem fortemente da ação gerencial para que ocorram de maneira absoluta.

$\mathrm{Na}$ teoria administrativa moderna, a decisão é considerada um processo contingencial, ou seja, não apenas lógico, sequencial e racional, mas também circunstancial, intuitivo e subjetivo. Cada decisão é um processo interativo que envolve informações, pessoas, funções, papéis, recursos e poder. A necessidade de escolha surge da percepção de um problema e depende da motivação e da criatividade do decisor para resolver esse problema, além de sua percepção sobre o contexto e os valores e critérios nos quais se baseia para tomar a decisão (PEREIRA; FONSECA, 2009).

A questão desta pesquisa é explicitada da seguinte forma: Como ocorre a tomada de decisão dos gestores na indústria de moda feminina de Belo Horizonte no processo de planejamento para o desenvolvimento de novos produtos? Tratou-se, pois, de investigar como 
ocorre a tomada de decisão de gestores da indústria de moda feminina de Belo Horizonte quanto à seleção de propostas para novas coleções.

Inúmeros são os desafios inerentes à indústria da moda, entre eles: processos complexos e fragmentados, desenvolvimento simultâneo de coleções, pressão para produzir peças alinhadas a tendências e a baixos custos, dificuldade de comunicação entre setores, ciclos de produção longos e consequente dificuldade em reagir rapidamente aos desejos dos consumidores (ARAÚJO, 2017).

Ao abordar tais questões no contexto da tomada de decisão, este artigo traz como contribuição a abertura para uma discussão, sustentada teoricamente, a respeito da importância de se questionar e tornar mais articulados os processos decisórios na indústria da moda. O estudo do processo de tomada de decisão tem se tornado cada vez mais importante, pois a eficácia das atividades que ocorrem nos negócios depende da forma como as decisões são amplamente concebidas e implementadas (OMARLI, 2017).

Embora seja um processo importante para a organização, a seleção de ideias é pouco pesquisada no meio acadêmico. Teza et al. (2015) realizaram uma revisão sistemática sobre o tema e constataram que $77 \%$ das publicações estavam relacionadas à geração de ideias e apenas $23 \%$ tratavam da seleção de ideias. Assim, considera-se que as decisões relativas à seleção de ideias para novos produtos seja um campo de investigação relevante tanto para as organizações como para a literatura científica.

\section{REFERENCIAL TEÓRICO}

Apresenta-se a seguir o aporte teórico requerido para a pesquisa, com a discussão de argumentos que sustentam o assunto tratado. São abordados os seguintes tópicos: a tomada de decisão nas organizações, a racionalidade nas decisões, participação da equipe na tomada de decisão e modelos de tomada de decisão.

\subsection{A tomada de decisão nas organizações}

A tomada de decisão constitui uma das funções mais importantes da gestão. $O$ processo de tomada de decisão é um dos mecanismos mais complexos do pensamento humano, pois envolve diversos fatores, cursos de ação e resultados. Trata-se de fazer escolhas a partir da reunião de informações e avaliação de soluções alternativas. As decisões não devem ser vistas como únicas e isoladas, mas como um processo composto por várias etapas. Ao tomar decisões, os gestores devem considerar o propósito do negócio para o um alto impacto em todos os planos de atividades e resultados da empresa (OMARLI, 2017).

A tomada de decisão é um processo que requer tempo, disponibilidade e a capacidade humana de processar informações. $\mathrm{Na}$ era do conhecimento, existe uma quantidade significativa de informações disponíveis, porém, nem todas elas são capazes de agregar valor aos objetivos da escolha. Portanto, o desafio do decisor não é obter informações, mas sim interpretá-las a fim de determinar sua utilidade para o processo decisório. A análise das alternativas implica ainda a avaliação de suas consequências, levando em consideração o grau de certeza e incerteza e o nível de risco envolvido na decisão (PEREIRA; FONSECA, 2009).

$\mathrm{Na}$ literatura, os autores descrevem de diferentes maneiras as etapas do processo de tomada de decisão. Para Simon (1977), ele é composto pelas fases de inteligência, projeto e escolha. No primeiro estágio, o responsável pela decisão busca obter informações ou conhecimento acerca do problema. Na etapa seguinte, tendo sido definido formalmente o problema, iniciam-se as atividades de elaboração e avaliação de alternativas na busca de potenciais soluções para o problema. Por fim, na fase de escolha, após análise das alternativas disponíveis, o tomador de decisão seleciona uma delas. 
O primeiro passo é a identificação e diagnóstico da situação; em seguida, é feita a avaliação das alternativas. Após a escolha da melhor possibilidade de ação, esta é implementada e posteriormente monitorada, gerando assim um feedback sobre a decisão tomada. Seja qual for o contexto em que ocorre o processo decisório, é importante que essa sequência de ações seja obedecida para que a organização tenha maior controle e segurança sobre suas ações (ROBBINS; JUDGE; SOBRAL, 2010).

Segundo Bazerman (2004), o processo decisório é realizado de maneira racional e deve envolver o estabelecimento de critérios, seguindo seis fases: i) definir perfeitamente o problema; ii) identificar todos os critérios; iii) ponderar acuradamente os critérios de acordo com a preferência do tomador da decisão; iv) reconhecer as alternativas relevantes; v) avaliar cada opção de acordo com cada critério, e vi) calcular e selecionar a que oferece maior valor. Karpinski (2020) ressalta que verificar os elementos referentes às etapas do processo decisório é fundamental, pois permite identificar os fatores que afetam o comportamento do sujeito em cada etapa da decisão, seja desde a identificação do problema até a implementação de soluções.

De acordo com Maximiano (2015), o processo decisório refere-se à sequência de etapas desde a identificação de determinada situação que requer algum tipo de decisão até o ato de escolher e colocar em prática uma ação ou solução, fechando assim o ciclo do processo. Compreender o processo decisório sob a forma de fases pode facilitar a vida do decisor, pois, reconhecendo a fase em que se encontra, ele tem a oportunidade de obter maior controle sobre a tomada de decisão, fazendo com que esta seja a melhor possível (OIH YU, 2017).

No caso da moda, o processo decisório para o desenvolvimento de novos produtos é entendido como um conjunto de atividades que envolve toda a organização e tem como propósito transformar as necessidades do consumidor em produtos economicamente viáveis. A indústria de confecção é composta pelos estágios de criação, produção e comercialização de produtos. O processo se inicia a partir da tomada de decisão estratégica, passa pelo projeto e fabricação do produto para então chegar ao consumidor final (CAPELASSI, 2010).

Ainda que ocorra de maneira estruturada, a tomada de decisão é complexa, pois quando um indivíduo toma uma decisão ele não tem conhecimento de todas as possíveis consequências da mesma. Em mercados dinâmicos como o da moda, o elemento de incerteza é sempre presente como resultado dessa falta de conhecimento prévio. Além disso, as percepções do decisor não refletem a realidade e variam conforme o momento. $\mathrm{O}$ resultado acarretado por esses fatores é, então, uma decisão satisfatória e não a melhor decisão (HUFF; PRYBUTOK, 2008).

Recentemente, cenários de negócios dinâmicos têm imposto diferentes necessidades aos processos de tomada de decisão, os quais devem se embasar descoberta de informações e conhecimento. Nesse sentido, os gestores precisam tomar decisões mais efetivas conforme o atual momento de alta demanda e dinâmica de mercado, gerando uma vantagem competitiva para a organização (SOUZA et al., 2020).

\subsection{A racionalidade nas decisões}

Na perspectiva de Weber, a racionalidade é o elemento central do conceito de ação social, podendo ser entendida como aquilo que caracteriza o seu sentido. A ação social pode ser determinada por meio de quatro tipos ideais de racionalidade, referentes a: i) fins: quando o sujeito age conforme suas expectativas em relação ao comportamento de objetos do mundo exterior e de outras pessoas, tomando essas expectativas como condições ou meios para alcançar fins próprios; ii) valores: quando a ação é orientada pelas próprias convicções do agente, sejam elas éticas, estéticas, religiosas ou de qualquer outra natureza; iii) afetos: 
quando a ação é inspirada em estados emocionais atuais, sem considerar meios ou fins a atingir; iv) tradição: quando a ação é guiada por costumes arraigados (WEBER, 1999).

$\mathrm{Na}$ discussão sobre as racionalidades, Weber traz uma importante contribuição ao argumenta que a ação social, como toda ação, pode ser movida por questões inspiradas pela tradição e pelo afeto, bem como por questões ligadas a valores de crença e ao cálculo racional meios-fins (BOLIS, MORIOKA, SZNELWAR, 2017). Com base no pensamento de Weber, Mannheim (1962) desenvolveu os conceitos de racionalidade funcional e racionalidade substantiva. A racionalidade funcional pressupõe a ordenação de meios para o alcance de fins específicos. O foco está no processo e nos instrumentos utilizados para o cumprimento de uma meta, sem que o agente tenha consciência dos objetivos predeterminados. Em contrapartida, a racionalidade substantiva admite uma valorização da inteligência dos indivíduos e sua capacidade de pensar, questionar e julgar os acontecimentos de maneira independente (MANNHEIM, 1962).

A racionalidade funcional ou instrumental, é uma ação embasada no cálculo, voltada para a consecução de finalidades relativas a interesses econômicos. Na lógica da racionalidade instrumental, prevalece a relação entre meios e fins, desconsiderando a qualidade e o conteúdo das ações. Já a racionalidade substantiva implica a concretização da ação com base não apenas em cálculos, mas também no contexto da interação social do indivíduo, permitindo o pleno desenvolvimento de suas potencialidades (RAMOS, 1989).

Habermas (1987) faz uma crítica à predominância da racionalidade instrumental na sociedade moderna no que diz respeito à supressão da interação social como meio de encontrar novas alternativas para a consecução de objetivos. Por esse motivo, o autor reformula o conceito de racionalidade, propondo um novo paradigma que estabelece uma relação entre trabalho e comunicação. Essa nova concepção consiste na razão comunicativa, a qual emerge de um contexto de diálogo, sem existência de coerção, de modo que os sujeitos possam expressar e contestar ideias por meio de argumentos.

Conforme o pensamento clássico da teoria econômica, uma condição para que o processo decisório funcione é que ele seja conduzido de forma racional. No entanto, essa premissa é inválida, pois a mente humana - que utiliza de métodos heurísticos para efetuar o reconhecimento, a busca e a seleção de informação - apresenta capacidade limitada de processar informação. Em outras palavras, o ser humano é intencionalmente racional, mas somente de forma limitada (SIMON, 1979).

A noção de racionalidade limitada serve, portanto, de base para explicar como as decisões realmente são tomadas. Em uma situação de escolha, o decisor tende a considerar modelos simplistas que fornecem opções evidentes e familiares, selecionando assim opções aceitáveis e finalizando a busca pela melhor alternativa possível. Essa aparente irracionalidade é decorrente do uso de heurísticas de decisão e das tendências causadas pela ordem em que as opções se apresentam ao decisor (ROBBINS, 2000).

$\mathrm{Na}$ teoria da racionalidade limitada, embora os gestores sustentem a abordagem matemática rigorosa no processo de tomada de decisões, eles também têm a oportunidade de enxergar a decisão em condições mais flexíveis. Nesse caso, é preciso que eles mantenham a mente aberta ao fazer escolhas e encontrar a explicação de sua melhor escolha. Todavia, baseada em razões subjetivas, a decisão é essencialmente qualitativa em sua natureza e tipicamente vaga (TARKA, 2018).

Pereira e Fonseca (2009) buscam estabelecer um equilíbrio entre as perspectivas objetiva e subjetiva da tomada de decisão ao afirmarem que não existe decisão absolutamente racional ou emocional. Segundo os autores, a decisão é sistêmica, multifacetada e multidisciplinar. Mesmo agindo intuitivamente, o decisor não deixa de seguir determinada lógica, envolvendo sempre o lado racional. O oposto também é válido, pois, por mais racional que seja, toda decisão se baseia em valores, crenças, experiências e emoções do decisor. 
Sendo assim, ao tomar decisões, o indivíduo age por inteiro, movido por atributos lógicos, biológicos, psicológicos, culturais, etc.

\subsection{Participação da equipe na tomada de decisão}

A respeito da figura do tomador de decisões, Maximiano (2006) afirma que a responsabilidade pelas decisões é primordialmente conferida aos gerentes ou pessoas que ocupam cargos de administradores. Todavia, isso não significa que todas as decisões devam ser tomadas por eles. Os gestores podem dividi-las com sua equipe e, conforme o grau de participação da mesma no processo decisório, as decisões classificam-se em três tipos: autocráticas, compartilhadas e delegadas, como mostra a Figura 1.

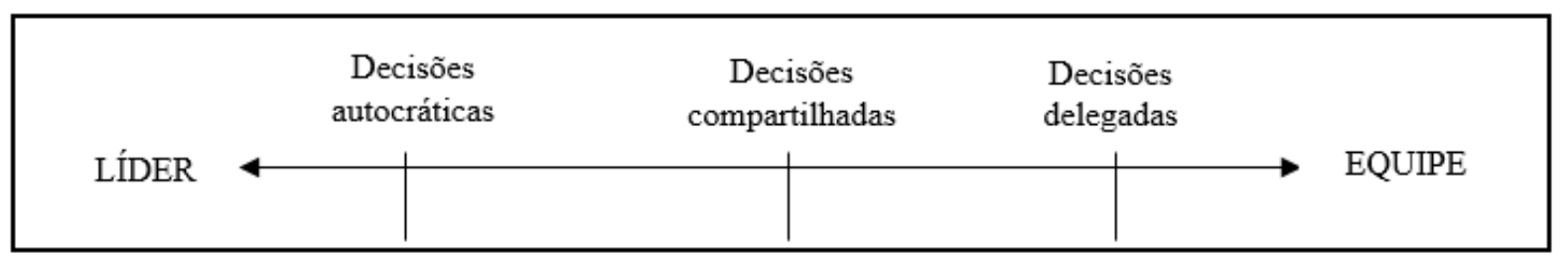

FIGURA 1 - Possibilidades de participação da equipe nas decisões

Fonte: Adaptado de Maximiano (2006)

Decisões autocráticas são aquelas tomadas de forma unilateral pelo gerente, não havendo participação da equipe no processo decisório. Do contrário, quando existe participação da equipe, as decisões podem ser compartilhadas, tomadas juntamente com os membros ou mesmo totalmente transferidas a eles, ocorrendo assim uma delegação (MAXIMIANO, 2006).

Pereira e Fonseca (2009) destacam que o aumento da participação no processo decisório (empowerment) estimula a autonomia da equipe, a motivação e a visão compartilhada, reduzindo a centralização das decisões ou o uso da autoridade no sentido vertical. A participação exerce um poder sobre as práticas e influencia fortemente a satisfação no trabalho e o comprometimento organizacional. Pesquisas envolvendo executivos de sucesso em países desenvolvidos apontaram que a chave para o sucesso nas organizações é o uso das opiniões dos funcionários na tomada de decisões (MOHSEN, SHARIF, 2020).

Para Martins et al. (2015), seja qual for o nível de envolvimento dos proprietários e sua equipe, a tomada de decisão é um processo cuja gestão depende do capital humano, pois não há organização que opere sem o trabalho e esforço das pessoas. No processo de desenvolver novos produtos, por exemplo, são elas que tomam as decisões e assumem os riscos, cabendo então às empresas tornar esse processo eficiente e voltado para a potencialização de seus resultados.

Tendo em vista a natureza dinâmica da moda, as decisões precisam ser tomadas em nível de gestão. Em uma empresa de moda, o processo de tomada de decisão deve levar em consideração, além do relatório de vendas e as tendências de mercado, uma atualização de informações relativas ao consumidor bem como uma análise cruzada com o pensamento dos designers. Essa prática pode levar ao aumento da satisfação do consumidor bem como proporcionar mais responsabilidade e distinção aos profissionais que fazem parte da equipe de desenvolvimento do produto (ROCHA, 2016).

\subsection{Modelos de tomada de decisão}

O processo decisório envolve diferentes modelos de tomada de decisão, que variam conforme cada tipo de situação, não havendo assim um único modelo ideal, mas sim, modelos 
adequados para possíveis ocasiões (ALENCAR, MERÇON, 2020). Por se tratar de uma das principais obras acerca do tema, destacam-se como principais os modelos analisados por Choo (2003): racional, processual, político e anárquico. Seja qual for o modelo de decisão, existem duas propriedades a serem consideradas: a estrutura e a clareza dos objetivos, as quais influenciam nas escolhas, e a incerteza ou quantidade de informações disponíveis sobre os métodos e processos adotados.

Os modelos de tomada de decisão são analisados por Choo (2003) ao longo de dois eixos: ambiguidade/conflito sobre objetivos e incerteza técnica, como apresentado na Figura 2. No eixo horizontal, quando a ambiguidade/conflito sobre objetivos é baixa, a decisão aproxima-se de uma solução de problema, norteada por um conjunto definido de objetivos e preferências. Se, contudo, a ambiguidade/conflito é alta, devem ser observados a oportunidade e o contexto, a partir de fatores como momento oportuno, influência e esforço envolvidos na escolha. No eixo vertical, quando há baixa incerteza técnica, a decisão tende a ser estruturada, com interesses bem definidos e orientada por regras e rotinas. Entretanto, quando a incerteza técnica é alta, a decisão configura-se em um processo dinâmico, carregado de mudanças e interrupções inesperadas.

\begin{tabular}{|c|c|c|c|c|}
\hline$\varpi$ & Baixa & \multicolumn{2}{|c|}{ AMBIGUIDADE/ CONFLITO SOBRE OBJETIVOS } & Alta \\
\hline 氠 & & $\begin{array}{l}\text { MODELO RACIONAL } \\
\text { Orientado para objetivos } \\
\text { Guiado por regras, rotinas e } \\
\text { programas de desempenho }\end{array}$ & $\begin{aligned} & \text { MODELC } \\
\checkmark & \text { Objetivos e ir } \\
\checkmark & \text { Certeza sobre } \\
& \text { preferidos }\end{aligned}$ & $\begin{array}{l}\text { es } \\
\text { ultados }\end{array}$ \\
\hline 黄 & & $\begin{array}{l}\text { MODELO PROCESSUAL } \\
\text { Orientado por objetivos } \\
\text { Múltiplas opções e soluções } \\
\text { alternativas }\end{array}$ & $\begin{array}{ll} & \text { MODELO } \\
\checkmark & \text { Objetivos são } \\
\checkmark & \text { Processos par } \\
& \text { obscuros }\end{array}$ & ros são \\
\hline
\end{tabular}

FIGURA 2 - Modelos de tomada de decisão

Fonte: Adaptado de Choo (2003)

O modelo racional, inicialmente desenvolvido por March e Simon (1975) e, posteriormente, ajustado por Cyert e March (1992), descreve a tomada de decisão como uma ação orientada para objetivos cujo comportamento de escolha é regulado por normas e rotinas, de modo que as atividades sejam exercidas de acordo com procedimentos racionais. Para os autores, as organizações se apoiam constantemente em padrões para tomar decisões. Ademais, os procedimentos operacionais são a memória da organização e oferecem estabilidade e orientação para decisões recorrentes.

Proposto por Mintzberg, Raisinghani e Théorêt (1976), o modelo processual esclarece as fases e ciclos que estruturam as atividades de decisão. Com ênfase na dinâmica dos comportamentos decisórios e na amplitude e complexidade das decisões estratégicas, o modelo compreende fases de decisão (identificação, desenvolvimento e seleção). O processo se inicia com o diagnóstico do problema, passa pela análise de múltiplas opções e termina com a seleção de uma alternativa. Também fazem parte do modelo as rotinas de apoio à decisão - que dizem respeito a controle, comunicação e políticas - e fatores dinâmicos como intervenções e feedback. 
No modelo político, desenvolvido por Allison (1972), a política é considerada como mecanismo de decisão. Utiliza-se a metáfora da tomada de decisão como um jogo, em que diferentes jogadores ocupam posições diferentes e exercem graus de influência distintos, de acordo com as regras e seu poder de barganha. Nesse modelo, os resultados das decisões estão mais relacionados às mudanças políticas do que ao processo racional de escolha.

Associado à expressão "lata de lixo" por Cohen, March e Olsen (1972), o modelo anárquico faz referência a um processo de decisão que apresenta regras pouco definidas ou até mesmo incoerentes. Nele, as organizações são consideradas "anarquias organizadas" em que diversos tipos de problemas e soluções são apontados pelos participantes à medida que são gerados. As situações de escolha caracterizam-se por preferências problemáticas, tecnologia obscura e participação fluída. As preferências, nesse caso, representam ideias esparsas e precisam ser descobertas em vez de serem previamente conhecidas. A tecnologia é obscura, uma vez que os procedimentos não são bem compreendidos pelos membros da organização e não há meios definidos para o alcance de objetivos. A participação torna-se fluída, pois há envolvimento das pessoas nas inúmeras atividades.

\section{METODOLOGIA E DELINEAMENTO DA PESQUISA}

Esta pesquisa esteve pautada na perspectiva naturalista e na compreensão da experiência humana sob a ótica interpretativista. Essa concepção considera o homem um agente social que influencia e é influenciado pela estrutura social. Suas percepções sobre a realidade são peculiares, podendo então haver diferentes interpretações de acordo com o observador e o seu posicionamento diante do fenômeno investigado. A noção de significado reforça a necessidade de se conduzir a análise com base no ponto de vista do ator da ação, e não do investigador (SILVA; GOBBI; SIMÃO, 2004).

Em relação à natureza, esta pesquisa possui abordagem qualitativa. Para Chizzotti (2006), uma pesquisa não pode ser resultado de observações distantes das significações que os sujeitos atribuem a seus atos. Pelo contrário, deve revelar o sentido social construído pelos indivíduos em suas interações cotidianas. A abordagem qualitativa parte do pressuposto de que o conhecimento não pode ser reduzido a um rol de dados isolados ligados a uma teoria explicativa, pois existe uma interdependência entre o sujeito e o objeto.

Quanto aos objetivos, esta é uma pesquisa descritiva. Segundo Triviños (2008), seu objetivo é descrever de maneira precisa os fatos e fenômenos de uma dada realidade, o que exige do pesquisador uma série de informações acerca do objeto investigado. Esse tipo de estudo requer o estabelecimento de técnicas que orientem a coleta e a análise de dados, de modo a conferir validade científica à pesquisa.

$\mathrm{O}$ instrumento de coleta de dados adotado foi a entrevista semiestruturada. Para Minayo (2010), a entrevista é o procedimento mais comum no trabalho de campo. Em um sentido amplo, ela pode ser entendida como uma conversa com propósitos bem definidos, por meio da qual podem ser obtidos dados objetivos e subjetivos. Sendo assim, utilizou-se um roteiro semiestruturado com base nos objetivos e fundamentação teórica da pesquisa. Foram elaboradas perguntas referentes a questões discutidas em cada tópico do referencial.

Foram realizadas sete entrevistas com duração média de 75 minutos, que foram gravadas e posteriormente transcritas. O perfil definido para o entrevistado foi o de proprietário, diretor ou gerente (designer/estilista) responsável pelas decisões acerca do planejamento das coleções. Para a seleção das empresas participantes, foram determinados os seguintes critérios: i) ser empresa industrial do ramo de confecção de vestuário feminino; ii) estar localizada em Belo Horizonte; e iii) ter design próprio com lançamento regular de coleções. 
Considerando-se uma amostra não probabilística, foi empregada a técnica snowball (bola de neve) como método de amostragem. Assim, o participante inicial da pesquisa indicou novos participantes e assim sucessivamente até que fosse alcançado o objetivo proposto. Optou-se pelo método de saturação dos dados, considerando uma amostragem teórica em que o número de sujeitos envolvidos foi determinado em razão de sua representatividade para a teoria, e não para a população. A quantidade de entrevistados estipulada foi a que proporcionou maior contribuição teórica para a pesquisa, sendo suficiente para que não ocorresse repetição de dados (FLICK, 2008).

A técnica escolhida para analisar os dados foi a análise de conteúdo. Bardin (2011) define a análise de conteúdo como o conjunto de procedimentos sistemáticos e objetivos que visam obter indicadores (quantitativos ou não) capazes de fornecer inferências de conhecimentos em relação ao conteúdo das mensagens. $\mathrm{O}$ método baseia-se em três etapas fundamentais: i) pré-análise; ii) exploração do material; e iii) tratamento dos resultados, inferência e interpretação. Tais etapas foram realizadas com o apoio do software QDA Miner, um programa de análise qualitativa que permite gerenciar, codificar e avaliar dados textuais e gráficos (PROVALIS RESEARCH, 2009). A definição dos códigos e categorias ocorreu a priori, com base nos conceitos do referencial teórico e na estrutura do roteiro de entrevista.

\section{ANÁLISE E DISCUSSÃO DOS RESULTADOS}

Apresentam-se nesta seção os resultados da pesquisa. Dentre as entrevistadas, quatro são proprietárias da empresa e três são estilistas da marca. Todas as participantes possuem formação em Design de Moda e trabalham nessa área há mais de cinco anos. No decorrer da análise, utilizaram-se números como referência às entrevistadas e às empresas a fím de preservar a identidade de ambas. A caracterização das entrevistadas e das empresas é apresentada no Quadro 1.

QUADRO 1 - Caracterização das entrevistadas e das empresas

\begin{tabular}{|c|c|c|c|c|}
\hline Entrevistada & Cargo & Formação & $\begin{array}{c}\text { Tempo de mercado } \\
\text { da empresa }\end{array}$ & Tipo de produto \\
\hline E1 & Proprietária & Design de Moda & 4 anos & Vestuário feminino casual \\
\hline E2 & Proprietária & Design de Moda & 6 anos & Vestuário feminino casual \\
\hline E3 & Proprietária & Design de Moda & 7 anos & Vestuário feminino casual \\
\hline E4 & Proprietária & Design de Moda & 3 anos & Vestuário feminino personalizado \\
\hline E5 & Estilista & Design de Moda & 30 anos & Vestuário feminino plus size \\
\hline E6 & $\begin{array}{c}\text { Designer e } \\
\text { gerente de PCP }\end{array}$ & Design de Moda & 30 anos & Vestuário feminino casual chic \\
\hline E7 & $\begin{array}{c}\text { Designer e } \\
\text { estilista }\end{array}$ & Design de Moda & 4 anos & Vestuário feminino casual chic \\
\hline
\end{tabular}

Fonte: Dados da pesquisa

A seguir, são abordados diversos aspectos envolvidos na tomada de decisão das empresas de moda. No Quadro 2, constam as categorias definidas na análise de conteúdo, sua definição e respectivos códigos.

QUADRO 2 - Categorias e códigos da análise de conteúdo

\begin{tabular}{|c|c|c|}
\hline Título da categoria & Definição & Códigos \\
\hline \multirow{2}{*}{ O decisor e seu papel } & $\begin{array}{c}\text { Refere-se à figura do decisor e aos } \\
\text { aspectos envolvidos na atuação dos } \\
\text { gestores como tomadores de decisão }\end{array}$ & Conhecimento dos processos \\
\cline { 3 - 3 } & Aborda as percepções e a & Agilidade na tomada de decisão \\
\hline Racionalidade e intuição do decisor & Feeling e julgamento pessoal \\
\hline
\end{tabular}




\begin{tabular}{|c|c|c|}
\hline & \multirow{2}{*}{$\begin{array}{l}\text { racionalidade/insights dos gestores } \\
\text { na tomada de decisão }\end{array}$} & Experiência no mercado \\
\hline & & Racionalidade limitada \\
\hline \multirow{3}{*}{ Participação da equipe } & \multirow{3}{*}{$\begin{array}{l}\text { Trata da influência da opinião dos } \\
\text { profissionais como o designer e o } \\
\text { estilista nas decisões }\end{array}$} & Cultura da empresa \\
\hline & & Visão compartilhada \\
\hline & & Autonomia e empowerment \\
\hline \multirow{3}{*}{ Modelo de tomada de decisão } & \multirow{3}{*}{$\begin{array}{c}\text { Descreve o modelo de decisão } \\
\text { encontrado na literatura que mais se } \\
\text { aproxima da realidade das empresas } \\
\text { investigadas }\end{array}$} & Identificação e seleção de ideias \\
\hline & & Modelo processual \\
\hline & & Grau de formalidade das decisões \\
\hline
\end{tabular}

Fonte: Dados da pesquisa.

\subsection{O decisor e seu papel}

Como afirma Maximiano (2006), a responsabilidade pela tomada de decisão é essencialmente atribuída ao gerente ou administrador. Na maioria das empresas de moda, segundo as respondentes, o gestor é o proprietário da marca, sendo o ocupante do cargo de diretor de estilo. Na fala da entrevistada 2, nota-se que embora tenha o apoio da equipe, a função de tomar decisão é do dono da marca: "Geralmente a diretora de estilo, né. É... na maioria das vezes, são os proprietários da marca. Então assim, eles contratam uma equipe pra ir trabalhar na parte de criação, mas eles é quem tomam as decisões".

A entrevistada 6 ressalta que há casos em que o proprietário é um administrador que encontrou uma oportunidade de investimento no mercado da moda, mas não necessariamente é um profissional dessa área. Portanto, para conduzir bem o negócio, conta com pessoas capacitadas para lhe fornecer auxílio na tomada de decisão. E, à medida que está em constante contato com a moda, adquire expertise para lidar com as mais diversas situações do cotidiano. Encarregada de tomar todas as decisões em sua empresa, a entrevistada 1 afirma que quando se fala em tomada de decisão, o leque de possibilidades é amplo, pois cada decisão é peculiar, uma vez que trata de um problema particular, parte de um setor diferente e envolve determinado grau de dificuldade. Assim, cada circunstância exige um comportamento específico do gestor, o qual faz o uso de variados mecanismos para a tomada de decisão.

[...] quando eu falo, por exemplo, de comercial, já é mais complicado, porque às vezes o que vai ser me passado, às vezes é uma, uma questão de... de gestão pessoal mesmo, algum problema assim. Então pra eu tomar uma decisão eu tenho que realmente ouvir tudo, observar, pra realmente chegar a uma conclusão. Quando se fala por exemplo, de produto, ah esse produto não tá vendendo, esse tá, eu consigo, porque eu tenho um relatório e um sistema que me mostra, eu consigo conferir, e tenho ali, contra dados não tem argumentos, então realmente esse produto não tá vendendo, vou tomar a decisão de tirar ele da, do meu mix de produtos. Então assim, são n, a cada tomada de decisão ela vai de acordo com o setor que ela tá sendo, que ela tá vindo, então a gente tem diferentes maneiras de tomar decisões (E1).

$\mathrm{Na}$ percepção da entrevistada 5, o proprietário muitas vezes não possui o conhecimento e a experiência necessários para tomar decisões em todas as áreas da empresa. Portanto, "o ideal seria, cada setor ter uma pessoa responsável com autonomia pra tomar decisões naquele setor, até mesmo porque, às vezes, quem é do financeiro não entende muito bem do estilo, então eu acho que não deveria ter autonomia pra tomar decisão em cima do estilo". Considerando que a tomada de decisão é um processo que exige tempo, disponibilidade e capacidade do gestor para processar e filtrar informações, como apontado por Pereira e Fonseca (2009), a designer acrescenta que trabalhar dessa forma agiliza o processo de tomada de decisão, o que é extremamente importante para o setor da moda, pois: 
[...] a gente nunca tem um tempo reserva na moda, a gente tá sempre trabalhando com o limite do limite, é, terminou uma coleção já tem que começar a desenhar outra... pra daí três meses já começar a colocar as primeiras peças piloto na mão dos fornecedores e os representantes, então tem que ser muito ágil, é isso que eu te falo, tem que tá acompanhando tudo que tá acontecendo pra não precisar parar pra pensar (E5).

Pacheco e Goldman (2019) apontam que respostas rápidas são elementos fundamentais para a sustentabilidade econômica da empresa. A entrevistada 3 concorda que o gestor deve ser ágil nas decisões para não perder o prazo de lançamento, desenvolvimento de catálogo e apresentação do produto aos lojistas, caso contrário, corre o risco de perder o cliente: "[...] essa questão do tempo é muito importante pra moda, porque se você faz uma coleção linda, maravilhosa, mas se você chegou com ela atrasada na loja, a loja já comprou de outros lugares". A entrevistada 4 atenta para o fato de que algumas decisões são mais complexas, exigem mais tempo e precisam ser tomadas com um cuidado maior em razão do impacto de suas consequências. Entretanto, ainda que sejam desafiadoras, essas decisões não podem ser tardias, pois devem acompanhar o ritmo do mercado.

Se for o lançamento de um produto novo, eu acho que você tem que ter mais cautela e pesquisar mais se vai ser isso mesmo porque o seu investimento vai ser maior. Mas também, é, as decisões feitas com cautela não podem demorar muito porque hoje é tudo muito acelerado né. Mas eu acho que é importante pesar as coisas (E4).

Diante de tais considerações, torna-se fundamentada a afirmação dos autores Huff e Prybutok (2008) de que a tomada de decisão é um ato complexo, já que ao fazer uma escolha o gestor assume riscos, dada a falta de conhecimento de suas possíveis consequências, especialmente em um mercado tão inconstante como o da moda.

\subsection{Racionalidade e intuição do decisor}

Conforme Souza (2020), mercados dinâmicos como o da moda implicam diferentes necessidades nos processos decisórios. Ao abordarem os fatores que influenciam a tomada de decisão, as entrevistadas mencionaram, sobretudo, a palavra feeling para se referir à intuição do gestor e aos aspectos que são determinantes para o seu posicionamento diante de uma situação que envolve decisão. Segundo a entrevistada 4, principalmente quando a marca tem pouco tempo de mercado, as decisões são tomadas com base no julgamento pessoal do decisor.

Ainda mais quando a marca é muito nova e você ainda não tem tantos dados nas mãos pra poder tomar as decisões, você tem que ir bem no feeling mesmo. Acho que a partir da hora que a marca já tem um tempo... e você já entende melhor, já tem dados... aí você consegue tomar uma decisão um pouco menos... é, baseado em você, e mais baseado nos dados (E4).

Relacionando a agilidade nas decisões e a intuição do decisor, a entrevistada 2 declara: "A questão de decisões rápidas, não necessariamente na moda né, é a intuição né, eu acho que a maioria delas, elas tão envolvendo a intuição do próprio empreendedor". Para a entrevistada 3, o feeling está ligado ao conhecimento do perfil do cliente: “[...] é bem o feeling mesmo que vai vender bem, vamo produzir mais dela, é... você pode, uma ou outra coisa te surpreender um pouco, mas tem coisa que você já sabe, que é a cara do cliente, que é o perfil...".

Para a entrevistada 1, já que no mercado da moda os produtos são desenvolvidos com certa antecedência e em um ambiente de imprevisibilidade, as decisões na verdade são apostas que resultam de um consenso entre os profissionais sobre o que deve ser produzido para o 
alcance de um considerável volume de vendas. Essa afirmação pode ser embasada pela visão de Simon (1979) sobre a racionalidade limitada - incapacidade de processar todas as informações disponíveis para a tomada de decisão - bem como pelo pensamento de Huff e Prybutok (2008) acerca da impossibilidade de conhecer todas as possíveis consequências de uma decisão.

[...] tem o feeling a todo tempo, por que? Porque a gente trabalha com coleções, fazendo uma coleção que vai ser lançada daqui um mês. Então quando a gente olha uma estampa ou um vestido, a gente fala assim, nossa, esse vai vender, não, esse não vai vender não, esse vai. A gente chega num acordo, ai será que vai, não vai? Ah não, vamo cortar. Então isso, a nossa, o nosso ramo, ele é o tempo inteiro assim (E1).

A empresária ainda afirma que assim como o feeling, a experiência no mercado é um fator que exerce impacto sobre a tomada de decisão, pois nos dias atuais consegue fazer escolhas mais sábias e com maior segurança. Ademais, cita que o decisor é influenciado até mesmo pela sua formação como indivíduo: "E depende também da educação, né, o seu histórico familiar, da criação que você teve né, tudo isso influencia diretamente". Tal afirmação reforça o pensamento de Pereira e Fonseca (2009): a decisão é influenciada pelo conhecimento do decisor (habilidade e experiência) e por suas peculiaridades lógicas, biológicas, psicológicas e culturais.

A entrevistada 7 acrescenta que a experiência permite ao profissional encontrar soluções alternativas caso ocorra algo inesperado em determinado processo, evitando assim que os resultados da empresa sejam negativamente afetados.

É... a experiência... o conhecimento daquilo que você produz... influencia muito pra você acertar, pra minimizar o impacto que pode ter. Suponhamos, eu comprei um tecido que ele não casa muito com o que tava proposto na minha coleção, mas se eu tenho a experiência de colocar acessórios... de colocar aplicações, bordados... que conversem com a minha coleção, eu já vou salvar aquela remessa de tecido [...] (E7).

Conforme os argumentos apresentados pelas respondentes, entende-se que, além de utilizar os dados disponíveis para a tomada de decisão, o decisor faz escolhas com base em sua intuição, crenças e experiências. Nesse sentido, considerando os tipos de racionalidade abordados na literatura, é possível verificar que, no caso da moda, há uma predominância da racionalidade substantiva. Ramos (1989) compreende essa racionalidade como aquela que envolve não apenas o cálculo dos fins, mas uma contextualização do indivíduo e, além disso, como ressaltado por Tarka (2018), permite ao gestor tomar decisões em condições mais flexíveis.

\subsection{Participação da equipe}

Como evidenciado por Martins et al. (2015), toda organização funciona por meio do trabalho e esforço das pessoas, portanto, a gestão da tomada de decisão depende do capital humano, seja qual for o seu grau de envolvimento no processo. Com base em sua experiência de mercado, a entrevistada 2 afirma que o grau de participação da equipe está ligado à cultura da empresa, normas e burocracias internas, portanto, em algumas empresas os diretores fazem reuniões, porém, não levam em conta a opinião dos funcionários. Entretanto, em um contexto geral, nas empresas de moda, o processo decisório é conduzido pelos proprietários juntamente com sua equipe, de modo que cada membro colabore conforme suas habilidades e competências. 
[...] em todos os casos que eu trabalhei, são criadores, então os donos também são criadores, eles são diretores de criação. Eles participam efetivamente, mas a equipe agrega né, com certeza, porque tá ali uma equipe, cada um com sua expertise, uma pra desenvolver jeans, a outra pra desenvolver estampa, o outro pra desenvolver shapes... e ela vai tá ali pra compilar tudo isso e entender o que ela quer pra marca dela, e colocar no mercado [...] (E2).

Maximiano (2006) determina que as escolhas feitas em conjunto podem ser chamadas de decisões compartilhadas. Na opinião da entrevistada 1, essa troca de ideias com os colaboradores é imprescindível, pois estes fornecem boa parte das informações necessárias para a tomada de decisão.

$\mathrm{Na}$ verdade, nossa equipe é a principal fonte de informação para a tomada de decisão. Então a gente divide a equipe em setores, claro né, a gente tem a equipe do comercial, a gente tem a equipe da produção, a gente tem a equipe do financeiro. E em cada ponto a gente sempre tem uma pessoa, que é um responsável maior, que tá passando pra gente as situações [...] (E1).

Para Mohsen e Sharif (2020), considerar os pontos de vista dos colaboradores na tomada de decisão é a chave para o sucesso das organizações. A entrevistada 7 explica que "[...] eles têm um conhecimento que é único, eles têm uma visão do que eles tão fazendo que... olha, se costurar desse jeito não vai dar certo, mas se fizer desse jeito ele vai funcionar melhor...". A entrevistada 3 concorda que um trabalho desenvolvido em conjunto resulta melhores decisões e consequentemente produtos de melhor qualidade, por isso sempre troca ideias com seus funcionários no momento da criação para verificar se será viável produzir as peças exatamente da forma como ela desenhou, pois, caso contrário: "[...] não justifica você ter uma equipe, se você vai resolver tudo sozinha".

Segundo a entrevistada 6, a autonomia na tomada de decisão é fruto da construção de uma relação de confiança e parceria, em que o funcionário ganha a confiança do proprietário à medida que incorpora o "DNA da marca" e consegue mostrar que é capaz de tomar decisões. Ocupante de um cargo de gerência, a designer conta como conquistou seu espaço na empresa:

[...] chegou um momento em que era necessário eu tomar decisões por minha própria autonomia, porque meu diretor tava viajando, tava fora do país, não conseguia falar, ou eu tomava aquela decisão, né, aí eu teria a responsabilidade de errar ou acertar, ou parava todo um processo, uma produção inteira, então seria uma responsabilidade muito grande. Então aí eu acho que é uma construção da relação, entre funcionário e empresa, e acho que o ideal pra isso é você conseguir absorver o DNA (E6).

Essa transferência de autonomia na tomada de decisão é denominada empowerment, processo que, segundo Pereira e Fonseca (2009), aumenta a motivação e a visão compartilhada da equipe. Entretanto, para que isso ocorra, é preciso haver uma quebra de paradigma, o que é mais difícil acontecer em empresas pequenas ou familiares, como declara a entrevistada 6:

[...] quando é uma empresa maior, e ela é setorizada, ela já começa de alguma forma a deliberar, né, então assim, ela já começa a dar autonomia; quando é uma empresa menor, familiar, muito pequena, fica tudo muito ali, né, mais fechado, então ela nem quer que você tenha tanta liberdade, porque ela quer tá no centro das decisões. Então vai depender muito essa relação, mas óbvio... pra você trabalhar, eu acho, pra que esse trabalho aconteça, é... dentro do prazo, dentro daquilo que a gente necessita, acho que a autonomia, né, ligado à confiança e ao bom senso do funcionário, é... essencial (E6). 
De acordo com as respondentes, no processo de desenvolvimento de uma coleção, geralmente, participam da tomada de decisão o proprietário - representando também a parte financeira na análise da viabilidade econômica - o estilista responsável pela coleção e uma pessoa que entenda de pesquisa de tendência, podendo ser um assistente de estilo/estagiário ou alguém contratado à parte.

Rocha (2016) aponta que nas empresas de moda as decisões devem ser tomadas em nível de gestão, a partir de informações sobre o mercado, relatórios e uma análise cruzada com o pensamento dos responsáveis pelo desenvolvimento das coleções. Quando questionadas a respeito da autonomia do designer/estilista na tomada de decisão, as entrevistadas afirmaram que esses profissionais influenciam nas escolhas, pois têm mais acesso ao mercado e ao público em relação aos demais funcionários que trabalham apenas internamente.

Segundo a entrevistada 5: "Vai depender da liberdade que ele tem dentro da empresa, mas se for uma empresa, igual umas que eu já trabalhei, que o dono confia completamente no estilista, ele tem liberdade pra... tipo, qualquer coisa dentro da empresa". Reafirmando a importância desse profissional, a entrevistada 6 conclui: "eu acho que o estilista influencia muito, até porque uma marca, pra contratar um estilista, ela tem que confiar, e quando a gente fala em DNA na verdade é o DNA do estilista, não é da marca”.

Estes são indícios de que o designer/estilista tem uma participação efetiva na tomada de decisão, o que contribui para a redução da centralização das decisões e da autoridade vertical à medida que o gestor torna compartilhado o processo decisório, como ressaltam Pereira e Fonseca (2009).

\subsection{Modelo de tomada de decisão}

Omarli (2017) afirma que as decisões não podem ser vistas de maneira isolada, mas como integrantes de um processo composto por diversas etapas. De acordo com as respondentes, os gestores seguem uma linha de raciocínio para identificar e selecionar ideias desde o processo criativo até a disponibilização dos novos produtos no mercado. Na moda, esse processo é chamado de desenvolvimento de coleção, como afirma a entrevistada 2: "Quando é uma coleção, quando é uma empresa que faz uma coleção elaborada... e tudo, na verdade, tem nome, que é o desenvolvimento de coleção. Ele começa na pesquisa, e termina... com o produto 'displayado' no chão de loja”.

Segundo a entrevistada 6, a identificação e seleção de ideias para o desenvolvimento de novos produtos ocorre a partir de um processo estruturado que tem início na criação do briefing, ou seja, um documento que reúne as especificações do produto e orienta a equipe na execução das etapas até a apresentação do projeto final.

\footnotetext{
A gente constrói aí né, um briefing, e a gente se reúne, isso todas as equipes, e a gente cria prazos... e cria toda uma linha do tempo pra que isso aconteça, então existe sim um planejamento, né, inicial, esse planejamento ele é acompanhado, esse planejamento, por exemplo, a gente trabalha com reuniões semanais, é... onde a gente tenta acompanhar o que cada setor conseguiu andar, o que tá cada setor tá fazendo, pra que chegue lá no final isso não seja um problema (E6).
}

Araújo (2017) destaca que um dos desafios na indústria da moda são os processos complexos e fragmentados. Para lidar com essa complexidade, Choo (2003) sugere que a organização crie padrões que orientem as rotinas e facilitem o trabalho do gestor. Na visão da entrevistada 5, tendo em vista o curto período entre a criação das peças até a sua apresentação ao mercado, é fundamental estabelecer tais padrões, pois, caso contrário, não é possível entregar a coleção em tempo hábil. Sendo assim, ainda que cada coleção seja desenvolvida 
em um cenário diferente, os procedimentos para se chegar aos resultados finais são os mesmos.

\begin{abstract}
No início de cada coleção é proposto um tema e dentro desse tema que é feito toda a pesquisa de tendência, primeiro faz a pesquisa de tendência, o que vai usar, escolhe o tema, faz toda uma pesquisa em tudo que envolve aquele tema, ah, por exemplo, um tema, hoje vai ser Belo Horizonte, aí a gente vai pesquisa Belo Horizonte e vai decidir sobre o que vai ser a coleção em Belo Horizonte, e aí a gente vai começar a orçar materiais, tecidos, aviamentos, que faça parte do que a gente tá pensando, até chegar numa coleção final que vai ser apresentada (E5).
\end{abstract}

Essas informações permitem inferir que a tomada de decisão nas empresas de moda aproxima-se do modelo processual, estabelecido por Mintzberg, Raisinghani e Théorêt (1976). Esse modelo pressupõe que as decisões estratégicas ocorrem em um ambiente dinâmico, seguindo três principais fases: identificação, desenvolvimento e seleção de ideias. Para Oih Yu (2017), essa estrutura de etapas facilita o trabalho do decisor, permitindo que ele consiga ter maior controle no processo decisório.

Quanto ao grau de formalidade do processo decisório, as entrevistadas afirmaram que nas empresas de moda a tomada de decisão ocorre tanto de maneira formal como informal. A entrevistada 4, que trabalhava como estilista de uma grande marca, afirma que nesta empresa esses dois tipos de decisões eram tomadas, sempre obedecendo a uma hierarquia: "Das duas formas, tinha reuniões mais formais e no dia a dia uma decisão ou outra era tomada de forma mais informal". A entrevistada 5 complementa: "Pode ter uma reunião, pra passar um briefing de marca, né, os orçamentos, os materiais que tem pra trabalhar, ou pode ser, olha, acabei de ter uma ideia aqui, é isso isso e isso, aprova? Aprovo. Na conversa, pelo celular".

Tratando dos processos decisórios relativos à sua empresa, a entrevistada 1 cita exemplos de decisões que possuem diferentes graus de formalidade:

Depende do setor, depende da... a gente tem uma situação aqui que vai, a gente vai tomar uma decisão de uma prática que a gente tinha, de até consignação né, de uma roupa que sai e não é vendida e a gente vai realmente impor pra equipe. Esse vai ser uma maneira, que você disse aí, formal. Vai ser formal. A gente vai sentar... Aí por exemplo, a gente tem outros tipos de decisões que a gente vai trabalhar aqui, de tentar captar uns corretores novos, aí ela já mais informal um pouco, que a gente vai aos poucos trabalhando. Então vai depender das circunstâncias, da situação (E1).

Na percepção da entrevistada 7, reuniões formais nem sempre são o melhor meio para se determinar as melhores alternativas, pois muitas vezes o que é decidido se torna inviável na prática “[...] geralmente faz reunião, mas nem sempre as reuniões são proveitosas, porque faz reuniões, toma decisões ali, e... depois essas decisões são descartadas [...]”. Em complemento, a entrevistada 6 associa a informalidade à necessidade de ser ágil nas decisões: "Eu acredito que na moda ainda é informal; a gente ainda tem muita coisa pra ajustar, porque... as coisas acontecem às vezes tão rápido que informalmente vai ser preciso tomar uma decisão".

Em síntese, nota-se a partir das falas das respondentes que, embora algumas decisões demandem certa formalidade, é possível admitir que o processo decisório de desenvolvimento de novos produtos na indústria da moda ocorre de cima para baixo e tem um caráter mais informal.

De acordo com Robbins, Judge e Sobral (2010), após a escolha das melhores alternativas, a decisão é implementada e monitorada, gerando um feedback para o decisor. A entrevistada 4 relata que a marca para a qual trabalhava era uma empresa grande e o contato direto com o cliente era quase inexistente, portanto, o feedback era obtido a partir dos relatórios de vendas. Entretanto, em relação à sua marca: "na minha empresa hoje o feedback vem totalmente do cliente". Na visão da entrevistada 5, o parecer mais importante é aquele 
concedido pelos vendedores, pois estes frequentemente se encontram próximos do cliente e conseguem esclarecer aos lojistas e estilistas os motivos das peças terem sido ou não aceitas pelo público.

\begin{abstract}
A maioria recebe pelas vendedoras do showroom. Elas têm um bom feedback, porque as pessoas vão comprar com elas e quem tá indo comprar com elas, já tem os clientes, os clientes que estão falando se estão gostando ou não. Tanto é que quando a estilista faz os primeiros esboços da coleção, sempre chama na reunião de equipe, sempre tem um vendedor [...] (E5).
\end{abstract}

A entrevistada 7 acrescenta que os lojistas também são capazes de fornecer feedback, já que estão ligados aos vendedores e conseguem ter uma boa percepção por meio do desempenho nas vendas: "Olha, algumas recebe pelo cliente direto, mas o que eu observo é que geralmente são dos lojistas mesmo, sabe, é tipo assim, e eu acho que dá pra sentir também pelo que volta, pelo que volta pra troca". Diante de tais relatos, observa-se que, seja qual for a sua origem, o feedback é um fator dinâmico que também faz parte do modelo processual de tomada de decisão proposto por Mintzberg, Raisinghani e Théorêt (1976), além das intervenções e rotinas que apoiam e controlam as decisões.

\title{
5 CONSIDERAÇÕES FINAIS
}

Este estudo foi realizado com o intuito de investigar como ocorre a tomada de decisão dos gestores na indústria de moda feminina de Belo Horizonte no processo de planejamento para o desenvolvimento de novos produtos. Considera-se que esse objetivo foi satisfatoriamente alcançado na medida em que foi descrita a tomada de decisão para o desenvolvimento de novas coleções. $O$ foco dessa caracterização esteve voltado para o papel do gestor, a sua racionalidade no momento da decisão, o grau de participação da equipe nos processos decisórios e o modelo de tomada de decisão frequentemente adotado na indústria da moda.

As decisões na indústria da moda envolvem muitas incertezas e se baseiam principalmente na intuição do decisor. Além disso, a experiência do gestor é considerada determinante para se fazer escolhas mais acertadas, pois, à medida que adquirem conhecimento ao longo dos anos, os profissionais passam a ter uma visão mais clara quanto às opções mais apropriadas em circunstâncias diversas.

$\mathrm{Na}$ indústria da moda, o responsável pela tomada de decisão geralmente é o proprietário da marca, ainda que este seja um administrador, e não necessariamente um profissional do ramo da moda. E, uma vez que não possui domínio sobre todas as áreas da organização, o gestor conta com o apoio de sua equipe para tomar decisões no acelerado ritmo exigido pelo mercado.

A importância da participação da equipe na tomada de decisão é atribuída ao fato de todas as tarefas estarem interligadas, o que torna necessário optar por alternativas que sejam adequadas a todos os setores. No processo de compartilhamento de decisões, o designer/estilista é apontado como um profissional que possui autonomia na tomada de decisão e participa ativamente do planejamento estratégico para o desenvolvimento de novas coleções.

Nas empresas pesquisadas, a identificação e seleção das ideias para o desenvolvimento de coleções acontece por meio de um processo estruturado, o que caracteriza o modelo processual de tomada de decisão. As decisões partem de cima para baixo e na maioria das vezes ocorrem de modo informal, tendo em vista o surgimento de imprevistos e a necessidade de resolver problemas rapidamente. O feedback das decisões é fornecido principalmente pelos relatórios de vendas, clientes, lojistas e vendedores. 
Além das contribuições teóricas acerca das análises, este estudo também resultou em implicações gerenciais práticas. No âmbito organizacional, as questões discutidas nesta pesquisa podem levar os gestores do mercado da moda a fazerem uma reflexão crítica sobre a tomada de decisão estratégica em suas marcas, com base no panorama atual da indústria da moda em Belo Horizonte fornecido pelas entrevistadas.

Em relação às limitações da pesquisa, evidencia-se, primeiramente, que o objeto de estudo foi investigado com o maior grau de profundidade possível dentro do recorte do estudo. Contudo, há de se considerar que a tomada de decisão é um tema abrangente, que pode ser pesquisado sob diversas perspectivas. Dessa forma, o levantamento de novos questionamentos bem como a extensão da pesquisa de campo ofereceriam maiores possibilidades de identificação de padrões inerentes à indústria da moda.

No estudo realizado, é possível mencionar como ponto fraco a não mensuração do caráter quantitativo da tomada de decisão nas empresas estudadas. Portanto, sugere-se que dados quantitativos sejam coletados para que, juntamente com os dados das entrevistas, forneçam uma caracterização mais consistente dos processos decisórios no setor da moda.

Por fim, uma vez que a pesquisa esteve voltada apenas para a tomada de decisão no planejamento de novas coleções, recomenda-se que também sejam analisados o desenvolvimento e comercialização dos produtos como forma de complementar o estudo dos processos decisórios na cadeia produtiva da moda. Além disso, o levantamento de dados secundários da indústria têxtil e de confecção também contribuiria para a caracterização do objeto de estudo. 


\section{REFERÊNCIAS}

ALENCAR, D. F.; MERÇON, L. A administração e a tomada de decisão na empresa familiar. Episteme Transversalis, v. 11, n. 1, 2020.

ALLISON, G. T. Essence of Decision: Explaining the Cuban Missile Crisis. Boston: Little Brown, 1972.

ALVES, R. Moda e desenvolvimento local: reconversões culturais na criação e confecção do jeans em Toritama - Pernambuco. 2009. 100 f. Dissertação (Mestrado em Extensão Rural e Desenvolvimento Local). Departamento de Educação, Universidade Federal Rural de Pernambuco, Pernambuco.

ARAÚJO, G. C. O design na indústria da moda no Brasil no século XXI: Uma proposta de design colaborativo. 2017. 212 f. Dissertação (Mestrado em Ciências). Programa de PósGraduação em Têxtil e Moda, Escola de Artes, Ciências e Humanidades, Universidade de São Paulo, São Paulo.

ARAÚJO, H. M. Práticas de melhoria de manufatura com curto ciclo de vida de produtos e imprevisibilidade de demanda: aplicação na indústria de vestuário de moda. 2013. 177 f. Dissertação (Mestrado em Engenharia de Produção). Programa de PósGraduação em Engenharia de Produção, Escola de Engenharia de São Carlos da Universidade de São Paulo, São Carlos.

BARDIN, L. Análise de conteúdo. Tradução Luís Antero Reto e Augusto Pinheiro. São Paulo: Edições 70, 2011.

BAZERMAN, M. H. Processo decisório: para cursos de administração e economia. Rio de Janeiro: Elsevier, 2004.

BOLIS, I.; MORIOKA, S. N.; SZNELWAR, L. I. Are we making decisions in a sustainable way? A comprehensive literature review about rationalities for sustainable development. Journal of Cleaner Production, v. 145, p. 310-322, 2017.

CAPELASSI, C. H. Metodologia projetual para produtos de moda e a sua interface com as tabelas de medidas do vestuário. 2010. 102 f. Dissertação (Mestrado em Design). Faculdade de Arquitetura, Artes e Comunicação da Universidade Estadual Paulista, Bauru.

CHIZZOTTI, A. Pesquisa em ciências humanas e sociais. 8. ed. São Paulo: Cortez, 2006.

CHOO, C. W. A organização do conhecimento: como as organizações usam a informação para criar conhecimento, construir conhecimento e tomar decisões. São Paulo: Senac, 2003.

COHEN M.; MARCH J.; OLSEN, J. A garbage can model of organizational choice. Administrative Science Quartely, v. 17, p 1-25, 1972.

CYERT, R. M.; MARCH, J. G. Behavioral theory of the firm. 2. ed. Oxford: Blackwell, 1992.

FLICK, U. Uma introdução à pesquisa qualitativa. Porto Alegre: Bookman, 2008. 
FUJITA, R. M. L. Economia solidária na indústria têxtil e de confecção: influência dos atributos relativos ao mito fundador da moda brasileira. 2017. 169 f. Dissertação Dissertação (Mestrado em Ciências). Programa de Pós-Graduação em Têxtil e Moda, Escola de Artes, Ciências e Humanidades, Universidade de São Paulo, São Paulo.

GODARD, F. Sociologia da moda. São Paulo: Senac, 2010.

HABERMAS, J. Técnica e ciência como ideologia. Lisboa: Edições 70, 1987.

HUFF; R. A.; PRYBUTOK, V. R. Information Systems Project Management Decision Making: The Influence of Experience and Risk Propensity. Project Management Journal, v. 39 , n. 2, p. 34-47, 2008.

KARPINSKI, A. C..; COGO, D. C.; ANTONELLI, R. A.; MEURER, A. M. Relationship between the self-efficacy and the stages of the decision-making process: analysis of the future managers' perception. Revista de Administração da UFSM, v. 13, n. 4, p. 792-807, 2020.

MANNHEIM, K. O homem e a sociedade: estudos sobre a estrutura social moderna. Rio de Janeiro: Zahar, 1962.

MARCH, J. G.; SIMON, H. A. Limites cognitivos da racionalidade. In: Teoria das organizações. Rio de Janeiro: FGV, 1975. p. 192-220.

MARTINS, V. M. C.; MARTINS, R. S. M.; SIEDENBERG, D. R.; GRIEBELER, M. P. D. Gestão da inovação em empresas que adotam diferentes processos de tomada de decisão. Gestão \& Tecnologia. Pedro Leopoldo, v. 15, n. 3, p. 211-244, 2015.

MAXIMIANO, A. C. A. Fundamentos da administração: introdução à teoria geral e aos processos da administração. 3. ed. Rio de Janeiro: LTC, 2015.

MAXIMIANO, A. C. A. Introdução à administração. 7. ed. São Paulo: Atlas, 2006.

MELO; M. O. B. C.; CAVALCANTI, G. A.; GONÇALVES, H. S.; DUARTE, S. T. V. G. Inovações tecnológicas na cadeia produtiva têxtil: análise e estudo de caso em indústria no nordeste do Brasil. Revista Produção Online, v. 7, n. 2, 2007.

MINAYO, M. C. S. (Org.). Pesquisa social: teoria, método e criatividade. 29. ed. Petrópolis: Vozes, 2010

MINTZBERG, H.; RAISINGHANI, D.; THÉORÊT, A. The structure of "unstructured" decision processes. Administrative Science Quarterly, v. 21, n. 2, p. 246-274, 1976.

MOHSEN, A.; SHARIF, O. Employee participation in decision making and itseffect on job satisfaction. International Journal of Research, v. 8, n. 7, p. 415-422, 2020.

OMARLI, S. Which Factors have an Impact on Managerial Decision-Making Process? An Integrated Framework. Essays in Economics and Business Studies, p. 83-93, 2017. 
PACHECO, M. C. R.; GOLDMAN, F. L. Modelos multicriteriais de apoio à decisão: o método AHP como auxilio à seleção de fornecedores em uma confecção. Brazilian Journal of Business, v. 1, n. 3, p. 979-1001, 2019.

PEREIRA, M. J. L. B.; FONSECA, J. G. M. Faces da Decisão: abordagem sistêmica do processo decisório. Rio de Janeiro: LTC, 2009.

PROVALIS RESEARCH. QDA Miner: Qualitative Data Analysis Software. User's Guide. Canadá: Provalis Research, 2009.

RAMOS, A. G. A nova ciência das organizações: uma reconceituação da riqueza das nações. Rio de Janeiro: Fundação Getúlio Vargas, 1989.

ROBBINS, S. P. Administração: mudanças e perspectivas. São Paulo: Saraiva, 2000.

ROBBINS, S. P.; JUDGE, T. A.; SOBRAL, F. Comportamento organizacional: teoria e prática no contexto brasileiro. 14. ed. São Paulo: Pearson Prentice Hall, 2010.

ROCHA, M. A. V. Consumidores, designers e gestores: aplicação do modelo da cadeia meios-fim para o desenvolvimento de produtos de moda-vestuário. ModaPalavra Eperiódico, v. 9, n. 17, p. 48-66, 2016.

SILVA, C. R.; GOBBI, B. C.; SIMÃO, A. A. Análise de conteúdo como uma ferramenta para a pesquisa qualitativa: descrição e aplicação do método. Organizações rurais \& Agroindustriais, v. 7, n. 1, p. 70-81, 2005.

SIMON, H. A. Comportamento Administrativo: estudo dos processos decisórios nas organizações administrativas. 3. ed. Rio de Janeiro: Fundação Getúlio Vargas, 1979.

SIMON, H. A. The new science of management decisions. Upper Saddle River: Prentice Hall, 1977.

SOUZA, M. L. H.; COSTA, C. A.; RAMOS, G. O.; RIGHI, R. R. A survey on decisionmaking based on system reliability in the context of Industry 4.0. Journal of Manufacturing Systems, v. 56, p. 133-156, 2020.

STEFANOVITZ, J. P. Contribuições ao estudo da gestão da inovação: proposição conceitual e estudos de caso. 2011. 197 f. Tese (Doutorado em Engenharia de Produção). Escola de Engenharia de São Carlos, Universidade de São Paulo, São Paulo.

TARKA, P. The views and perceptions of managers on the role of marketing research in decision making. International Journal of Market Research, v. 60, n. 1, p. 67-87, 2018.

TEZA, P.; DANDOLINI, G., SOUZA, J. A.; MIGUEZ, V. B.; FERNANDES, R. F., MIGUEL, P. A. C. Modelos de front end da inovação: similaridades, diferenças e perspectivas de pesquisa. Production, v. 25 n.4, 2015.

TRIVIÑOS, A. N. S. Introdução à pesquisa em ciências sociais: a pesquisa qualitativa em educação. São Paulo: Atlas, 2008. 
WEBER, M. Economia e sociedade: fundamentos da sociologia compreensiva. Vol. 1. Brasília: UnB, 1999.

OIH YU, A. S. (coord.). Tomada de Decisão nas Organizações: uma visão multidisciplinar. São Paulo. Saraiva, 2017. 